\title{
A força do cinema para a massificação ou para a promoção da diversidade cultural
}

\author{
La fuerza del cine para la masificación o para la promoción de la \\ diversidad cultural
}

The strength of cinema for the massification or for the promotion of cultural diversity

\author{
MSc. Cecília Leão Oderich ${ }^{1}$ \\ Dr.a Mariana Baldi ${ }^{2}$
}

\begin{abstract}
Resumo
A imagem influencia a compreensão, o conhecimento, a formação ideológica de indivíduos e grupos. Este trabalho apresenta um ensaio que analisa a força do cinema como arte que pode tanto legitimar padrões em processos de apropriação, padronização e massificação cultural, quanto pode se constituir como um espaço de inclusão, de crítica, de diversidade cultural e diálogo intercultural. São apresentados exemplos de filmes e os desafios dos cinemas nacionais e do cinema independente quando buscam além da hegemonia do visual. A perspectivação sobre diferentes temas, desde questões étnicas, da obesidade, do colonialismo, da escolarização, da "deformidade", por exemplo, pode ocorrer a partir do cinema de massa ou do cinema independente. A pesquisa sobre cinema pode ajudar na crítica anticolonizadora, no diálogo intercultural e na ampliação da tomada de consciência sobre a importância da arte e do cinema nas forças que conjuminam em modelos e padrões para uma suposta normalidade ou sucesso, na busca por relações menos estereotipadas.
\end{abstract}

Palavras-Chave: cinema, cinema independente, diversidade cultural, massificação cultural.

\section{Resumen}

La imagen influye en la comprensión, el conocimiento, la formación ideológica de los individuos y grupos. En este trabajo se presenta un ensayo que analiza la fuerza del cine como arte que puede legitimar tanto estándares en procesos de apropiación, estandarización e masificación cultural, como puede ser un espacio inclusivo, de la crítica, de la diversidad cultural y el diálogo intercultural. Son presentados ejemplos de películas y los retos de los cines nacionales y cine independiente cuando se buscan más allá de la hegemonía de lo visual. La perspectiva sobre diferentes temas, desde el origen étnico, la obesidad, el colonialismo, la educación, la "deformidad", por ejemplo, puede ocurrir desde el cine de masas o cine independiente. La investigación sobre el cine puede ayudar en la crítica colonizadora, en el diálogo intercultural y la expansión de la conciencia de la

\footnotetext{
${ }^{1}$ Doutoranda em Estudos Organizacionais PPGA/UFRGS - Universidade Federal do Rio Grande do Sul; Porto Alegre, RS, Brasil; cloderich@ig.com.br.

${ }^{2}$ Professora Doutora PPGA/UFRGS - Universidade Federal do Rio Grande do Sul; Porto Alegre, RS, Brasil; marianabaldi@ufrgs.br.

Trabalho apresentado no I Seminário Latino-Americano de Estudos em Cultura - SEMLACult, Foz do Iguaçu/PR, Brasil, 2017.
} 
importancia del arte y el cine en las fuerzas que conjuminam modelos y normas para una supuesta normalidado el éxit, en la búsqueda de relaciones menos estereotipadas.

Palabras claves: el cine, el cine independiente, la diversidad cultural, la masificación cultural.

\begin{abstract}
The image influences the understanding, the knowledge, the ideological formation of individuals and groups. This paper presents an essay that analyzes the force of cinema as an art that can either legitimize patterns in processes of cultural appropriation, standardization and massification, or can be constituted as an area of inclusion, criticism, cultural diversity and intercultural dialogue. Examples of films and the challenges of national cinemas and independent cinema are presented when seeking beyond the hegemony of the visual. The perspective on different themes, from ethnic issues, obesity, colonialism, schooling, "deformity", for example, can occur from mass cinema or independent cinema. Film research can help in anticolonizing criticism, intercultural dialogue, and broadening awareness of the importance of art and film in the forces that combine in models and patterns for supposed normality or success in the search for less stereotyped relationships.
\end{abstract}

Keywords: Cinema, independent cinema, cultural diversity, cultural massification.

\title{
1. Introdução
}

A força da imagem influencia a percepção das pessoas em relações de materialidade e de subjetividade. A imagem, o som, o dito "realismo" cinematográfico ou a criação da fantasia e da ilusão impactam na compreensão, no conhecimento, na formação ideológica de indivíduos e grupos. Este trabalho apresenta uma análise sobre a importância do cinema como arte que pode tanto legitimar padrões que se tornam "socialmente aceitos" em processos de apropriação, padronização e massificação cultural, geralmente atrelado a uma imagem estadunidense ou eurocêntrica, quanto a se constituir como um espaço de inclusão de "novas vozes", de crítica, de diversidade cultural e diálogo intercultural.

Este trabalho, assim, constitui um ensaio teórico a partir de estudos sobre arte e cinema, com reflexões acerca de filmes, cujo objetivo inicial é analisar o cinema enquanto arte que influencia e legitima padrões culturais, ou também como um espaço de expressão da diversidade cultural.

\section{Cinema: a arte e a idealização}

O cinema pode mostrar a força da arte na reflexão quanto à diversidade cultural, abrindo espaços de diálogo e buscando significados de alguma forma inter-relacionados política, econômica e socialmente. O cinema independente, por exemplo, dadas as atuais 
facilidades tecnológicas de produção de baixo custo, pode possibilitar a expressão artística e cultural e para novas formas de manifestação e pertencimento, fora de uma suposta massificação social. O cinema é estudado pelo viés da sua influência ao reforçar sistemas e ideologias, pois a arte, assim com a educação, não é apolítica. Mesmo a aparente ausência de política é uma posição política, ou seja, mesmo quando os artistas não têm uma posição política consciente e clara para si mesmos e sobre suas obras, fazem política através do seu trabalho.

Anita Simis (2015), no livro Estado e Cinema no Brasil, coloca uma citação da Revista Para Todos, de 1925, associando o cinema ao "mais poderoso instrumento de propaganda até aqui arquitetado pelo engenho humano" acrescentando que "por isso mesmo encarniçadamente se disputam os mais avançados entre os povos civilizados” (p. 39). Sem entrar na discussão sobre que significa, ou não, povos civilizados, a questão aqui colocada traz a força da influência do cinema na cultura e na sociedade.

Hennebelle cita Carlo Lizzani (1978, p. 64), que faz uma análise relevante para a compreensão do setor cinematográfico em diferentes nações:

A autonomia da linguagem cinematográfica não significa que o cinema se destaque da cultura do seu país. Podemos mesmo dizer que, quanto mais a sintaxe do filme se precisa, mais o cinema se enraíza na tradição nacional dos diferentes povos. Se o cinema é uma conquista geral da humanidade que, na sua marcha para a dominação da técnica, consegue precisamente fazer da máquina um novo instrumento de atividade artística, um meio de aumentar a atividade cultural, o cinema nasce, nos diferentes povos, da coincidência progressiva de uma linguagem cinematográfica sempre mais autônoma e mais flexível com a cultura nacional de cada país. A criação da linguagem cinematográfica não é um processo abstrato, capaz de acontecer em qualquer lugar e sob quaisquer condições.

Por outro lado, muitas vezes o cinema de massa tem grande efeito na idealização de imagens de sucesso, de beleza, com o famoso "happy end", sem o dito realismo sociológico. O conceito de indústria cultural (ADORNO, 1975, ADORNO E HORKHEIMER, 1947) traz a discussão sobre fragmentação, divisão do trabalho, previsibilidade, funcionalidade, replicabilidade e rentabilidade no campo da arte. $\mathrm{O}$ cinema, pela evidente aplicação tecnológica, é uma arte representativa neste debate. Em uma abordagem sociológica, a massificação, ou a analogia a uma sociedade de massas se refere a uma conjuntura "onde os desejos e os interesses de vida dos indivíduos são produzidos em massa, como em uma grande fábrica de pessoas" (ANDRADE, 2017, p.1). Neste sentido, pode-se pensar a indústria cultural como uma forma de padronização dos gostos e desejos dos seres humanos, voltando-os para o consumo, a vida tendo como fim o trabalho, sendo a diversão uma forma de relaxar, em um caminho de massificação das pessoas. Além disso, se 
as pessoas pensam de forma parecida, diminuem os confrontos e conflitos, e o foco segue no desejo de consumir, o que pode ser considerado um tipo de alienação. Ao discorrer sobre a sociedade de massas, Andrade (2017) lembra a obra de Huxley, Admirável Mundo Novo (1932), romance que aborda as possibilidades de uma suposta tecnologia reprodutiva com manipulação psicológica, condicionamento que remete ao que chamamos de sociedade de massa.

Já a busca pela expressão artística e pela diversidade pode ser um percurso que alerta para a massificação e promove a reflexão existencial e a diversidade cultural. Em seu texto Crítica da Imagem Eurocêntrica, Shohat e Stam (2006) exemplificam e analisam de modo esclarecedor o efeito do cinema, o qual pode ser no sentido da massificação ou da expressão da diversidade. Os autores mencionam diversos filmes e alertam para aa propagação e idealização da imagem eurocêntrica, argumentam que o que é intitulado como universal geralmente é aquilo que é palatável ao espectador ocidental, especialmente europeu e norte americano, a exemplo da premiação do Oscar, quando há plateia global e produto quase totalmente norte americano.

A arte é uma enunciação situada historicamente. Há uma batalha sobre o significado, sobre visões de mundo. O chamado realismo progressista no cinema combate representações hegemônicas, ou seja, é o cinema expressando maior diversidade, complexidade e realismo. No universo do discurso colonialista, as metáforas e os tropos (emprego da palavra em sentido figurado, "a alma do discurso") e motivos alegóricos exerceram um papel fundamental na "figuração" da superioridade europeia. Por exemplo, o tropo da infantilização representa os colonizados como se corporificassem um estágio primitivo do progresso humano individual ou do vasto desenvolvimento cultural. O negro que entra em contato com os brancos, de acordo com um romance belga de 1868, "perde seu caráter bárbaro, mantendo somente as qualidades infantis dos habitantes da floresta”, em uma clara relação dos negros ou com a barbárie, ou com o infantilismo (SHOHAT \& STAM, 2006). As narrativas dominantes trazem uma mentalidade imperial e um tipo de racionalidade, por exemplo manifestando valores como a simetria, a continuidade, os efeitos especiais, que seduzem e intimidam cineastas e espectadores do chamado Terceiro Mundo, e o muito esperado happy end.

Os cinemas nacionais têm o desafio de fazer diferente ou além da hegemonia do visual e de romper as expectativas estereotípicas da plateia, evitando cair em essencialismos ou moralismos. Neste sentido, busca-se "considerar um conjunto múltiplo de vozes, 
cultivando as diferenças culturais e suprimindo desigualdades sociais" (SHOHAT \& STAM, 2006, p. 312).

Por exemplo, temos grupos de cinema independente desenvolvendo filmes que abordam questões a partir da realidade percebida por pessoas e grupos, um exemplo é o filme de curta-metragem Kbela, cuja diretora Yasmin Thayná, coloca como sendo até certo ponto auto-biográfico. O curta aborda o cabelo negro, o preconceito vivenciado, inclusive o autopreconceito, as meninas desde pequenas aprendendo a buscar formas de alisar o cabelo, enfim, a relação das pessoas com o cabelo em um contexto onde se privilegia a beleza da imagem eurocêntrica. Este tipo de filme pode levar, aos poucos, a uma relação diferente das pessoas negras com o seu cabelo, inclusive no sentido de poder e de construção da autoestima. As pessoas que têm empatia, negras ou não, ao terem contato com o audiovisual, percebem uma realidade diferente da sua, ou podem repensar a própria realidade e agir diferente, o que aos poucos constrói novas relações e percepções de beleza e de poder. Tiburi (2016) coloca que o filme é politização estética, uma resistência poética.

Muitos outros filmes podem influenciar na relação e no entendimento das pessoas a partir do momento em que proporcionam uma aproximação com determinadas experiências que muitas vezes as pessoas não têm. Ou seja, o cinema inclui em determinada realidade quem não tem aquele tipo de experiência, e pode ajudar na auto-compreensão de quem tem.

Diversos documentários podem ampliar a visão sobre questões sociais relevantes para cada momento histórico. Um exemplo é o documentário Muito Além do Peso, 2012, de Maria Farinha e do Instituto Alana, que aborda a obesidade infantil e a comunicação mercadológica sobre alimentos dirigida ao público infantil. O filme sensibiliza sobre problemas decorrentes do consumismo na infância. Vale destacar que cerca de $33 \%$ das crianças brasileiras têm sobrepeso (http://www.muitoalemdopeso.com.br/).

O documentário Olhar Estrangeiro, 2006, de Lucia Murat, questiona como a indústria cinematográfica internacional, muitas vezes, reforça estereótipos, clichês e preconceitos em relação ao Brasil, mostrando comentários e trechos de filmes como Lambada, A Dança Proibida e Anaconda.

Já o documentário Escolarizando o Mundo, 2010, dirigido por Carol Black, por exemplo, incita uma reflexão sobre a suposta superioridade cultural embutida no discurso de projetos educacionais e questiona as definições de riqueza e pobreza, de conhecimento e de ignorância, na contemporaneidade. Muitas vezes, escolas podem influenciar na desvalorização de conhecimentos de comunidades tradicionais sustentáveis em prol de 
conhecimentos que levam a uma dependência e, portanto, sujeição, ao mercado de trabalho industrial e comercial.

Já filmes como XXY, 2008, de Lucia Puenzo, problematizam a questão da intersexualidade, ou o hermafroditismo, uma realidade desconhecida para a maioria das pessoas. Um exemplo curioso é o filme Freaks, de 1932, de Ted Browning. O filme, segundo Courtine (2006), foi considerado inclassificável ao romper radicalmente com o horror tranquilizante das convenções dos filmes de terror, e é um marco na história das representações do corpo anormal, de pessoas teratológicas, das percepções da deformidade humana. O filme, que foi um desastre de bilheteria, muda a sensibilidade ao mostrar uma história na qual a beleza física pode dissimular uma feiura moral, e a deformidade do corpo pode abrigar sentimentos humanos.

Os "estranhos" são aqueles que não se encaixam no mapa cognitivo, moral ou estético do mundo, por isso geram malestar quando há predomínio de uma lógica moderna, positivista, normativa.

\begin{abstract}
Mas a dificuldade essencial veio da natureza do próprio filme, portador de todas as contradições e ambiguidades de um momento de transição cultural: enquanto o cinema permite e as sensibilidades solicitam o mergulho dos olhares em um universo das deformidades corporais, mostrado de longe, Freaks constrói um mundo visual de extremo realismo teratológico, simula proximidades de voyeurismo de parque de diversão. (COURTINE, 2006, p. 322)
\end{abstract}

Já em 1938 ocorre a verdadeira virada na história do dito monstruoso, quando os estúdios Disney lançam o longa-metragem Branca de Neve e os sete anões. "Percebeu já nos anos 1940 o lucro que se podia tirar da indústria dos produtos derivados do cinema e transformou as ficções monstruosas em artigos de consumo para todo tipo de público, comercializando esses objetos" (COURTINE, 2006, p. 328), no caso, referindo-se a brinquedos, chocolates, bonecas, figurinhas, roupas e bonés. "Os monstros se dividem agora entre bonzinhos extraterrestres e ogros benevolentes" (p. 329). Ou seja, dependendo da abordagem, filmes que trazem temáticas "diferentes" até podem se tornar palatáveis ao público e "vendáveis".

A percepção e/ou reperspectivação sobre diferentes temas, como a questão do cabelo negro, da obesidade, do colonialismo, da escolarização, da "deformidade", podem ocorrer a partir do cinema em geral, seja de filmes do cinema de massa, do cinema industrial, hollywoodiano, ou do cinema independente. Mas como geralmente o cinema de massa busca temáticas que "agradem" e sejam mais "vendáveis", assim como as novelas, predominantemente tem estruturas narrativas que abordam o "normal" ou "normativo" 
daquele momento. Assim, muitas vezes o cinema de massa não aborda, ou então suaviza ou aborda de forma estereotipada, temas que sejam polêmicos, não palatáveis ou fora do mainstream.

\section{Cinema nacional e cinema independente: em busca de trajetórias pela diversidade}

Os cinemas nacionais e o cinema independente podem, ou não, tratar de questões sociais advindas da sua realidade, que é diversa, influenciando na própria percepção e construção desta realidade. Na América Latina, há um projeto público alavancado pelo governo colombiano através do site Retina Latina. Trata-se de uma plataforma digital de difusão, promoção e distribuição do cinema Latinoamericano, o qual disponibiliza gratuitamente filmes latinos online. O site disponibiliza 48 longas e 29 curta-metragens, e já conta com mais de 10.000 usuários registrados. O projeto busca novos públicos para o cinema latinoamericano, bem como a consolidação do público já existente. Além da Colômbia, vários países estão envolvidos: Bolívia, Equador, Perú, México e Uruguai. Os filmes abordam temas diversos, mas percebe-se a predominância de conteúdos que abrangem questões locais, por exemplo, a vida cotidiana no interior, as etnias da região e suas tradições, disputas por terras e por poder, problemas ambientais e sociais, questões sobre transexualidade.

O estudo sobre o cinema ajuda no sentido de não sermos meros reprodutores de um estilo de vida, a "explorar as experiências (efeitos, relações) em torno de como o que vemos nos conforma, faz-nos ser o que os outros querem que sejamos, e podemos elaborar respostas não reprodutivas diante do efeito desses olhares" (HERNÁNDEZ, 2013, p. 91).

Podemos pensar nas configurações dominantes neste momento, que constituem e são constituídas no aqui e agora. A pesquisa com e sobre imagens, neste caso, pode ajudar, mediante a contextualização e a crítica anticolonizadora, a "explorar as experiências (efeitos, relações) em torno de como o que vemos nos conforma, faz-nos ser o que os outros querem que sejamos, e podemos elaborar respostas não reprodutivas diante do efeito desses olhares" (HERNÁNDEZ, 2013, p. 91).

É importante problematizar e questionar a normatividade, cientes de que os discursos não carregam uma única verdade, mas têm uma história de práticas e relações de poder. A arte pode ser um espaço de "utilidade do inútil" (ORDINE, 2016), na condição de não submissão às necessidades funcionais, pelo menos quando se mantém em esfera de não sujeição à padronização. 
Albuquerque Jr. (2009), ao comentar sobre a obra A Metamorfose, de Kafka, coloca:

Como na própria vida do autor, havia cada vez menos lugar para a arte, para a criatividade, para o devaneio, para a fantasia, numa sociedade do ponto e da contabilidade, do emprego a salário, de um Estado cada vez mais presente e gigantesco, se espalhando por todas as fimbrias do social através de seus agentes. O ser animal permite ao personagem de Kafka o estranhamento absoluto diante dessa identidade que pesava cada vez mais sobre todos: a de ser Homem, o que implicava, cada vez mais, em ser europeu, em ser branco, em ser homem, em ser heterossexual, em ser burguês, em ser trabalhador, em ser produtivo, em ser belo, em ter sucesso, em ser racional, em ter família, em ser um atleta, em ser esperto, em ser rico. (ALBUQUERQUE Jr., 2009, p. 109-110)

Enfim, é relevante a busca pela ampliação da consciência sobre a importância da arte e do cinema, considerado a sétima arte, nas forças que conjuminam modelos e padrões para uma suposta normalidade ou sucesso. O cinema pode influenciar no sentido de maior compreensão da diversidade cultural, de maior diálogo intercultural e na busca por relações menos estereotipadas, modeladoras e normativas, podendo se constituir como um espaço de questionamento, de inclusão, de crítica anticolonizadora, ou simplesmente um espaço para a livre expressão artística.

\section{Referências}

ADORNO, Theodor W. A indústria cultural. In: COHN, Gabriel. Comunicação e Indústria Cultural. São Paulo: nacional, 1975.

ADORNO, Theodor W; HORKHEIMER, Max. Dialética do Esclarecimento. $3^{\circ}$ Ed. Rio de Janeiro: Editora Zahar, 1947.

ALBUQUERQUE Jr., Durval Muniz. A bela ou a fera: os corpos entre a identidade da anomalia e a anomalia da identidade. In: RAGO, Margareth; VEIGA-NETO, Alfredo (Orgs.). Para uma vida não-fascista. Belo Horizonte: Autêntica, 2009. (p.95-115).

ANDRADE, Rafael. Sociedade de Massas. Infoescola - Sociologia. Disponível em: http://www.infoescola.com/sociologia/sociedade-de-massas/ Acesso em: 19 de julho de 2017.

COURTINE, Jean-Jacques. História e antropologia culturais da deformidade. In: CORBIN, Alain; COURTINE, Jean-Jacques; VIGARELLO, Georges (Orgs.). História do corpo 3 - as mutações do olhar: o século XX. Petrópolis: Vozes, 2006.

HENNEBELLE, Guy. Os cinemas nacionais contra Hollywood. Rio de Janeiro: Editora Paz e terra, 1978. 
HERNÁNDEZ, Fernando. Pesquisar com imagens, pesquisar sobre imagens: revelar aquilo que permanece invisível nas pedagogias da cultura visual. In: MARTINS, Raimundo, TOURINHO, Irene (orgs.). Processos \& práticas de pesquisa em cultura visual \& educação. Santa Maria: UFSM, 2013. p. 77-95.

ORDINE, Nuccio. A Utilidade do Inútil - Um Manifesto. Rio de janeiro: Zahar, 2016.

RETINA LATINA. Plataforma digital de difusão e promoção do cinema Latino americano. Disponível em: http://www.retinalatina.org/

SHOHAT, Ella; STAM, Robert. Crítica da imagem eurocêntrica. São Paulo: Cosac e Naif, 2006.

SIMIS, Anita. Estado e Cinema no Brasil. São Paulo: UNESP, 2015.

TIBURI, Márcia. Kbela, o filme - de Yasmin-Thayná. Revista Cult. Disponível em: http://revistacult.uol.com.br/home/2015/10/kbela-o-filme-de-yasmin-thayna/ Acesso em: 06/07/2016. 